\section{Commentary: It takes a village}

\author{
Carolyn K. Landolfo, $\mathrm{MD},{ }^{\mathrm{a}}$ and \\ Kevin P. Landolfo, $\mathrm{MD}^{\mathrm{b}}$
}

Hospital readmissions following coronary artery bypass grafting (CABG) generate unfavorable outcomes with high financial costs. ${ }^{1,2}$ Due to high readmission rates in the Medicare population, The Centers for Medicare and Medicaid Services enacted the Hospital Readmissions Reduction Program, which penalizes inpatient hospital practices with excessive readmission rates. ${ }^{3}$ Deo and colleagues ${ }^{4}$ demonstrate the positive influence of home health care (HHC) in reducing 30-day readmission following CABG.

The National Readmission Database queried over 3 years (2012-2014) identified 204,184 patients discharged to home following isolated CABG, of which $42.2 \%$ received $\mathrm{HHC}$ (ie, the $\mathrm{HHC}+$ group). A propensity analysis was used to match 66,210 patient-pairs with similar demographic and clinical data in the HHC + and HHC- (ie, those without HHC) cohorts.

HHC significantly reduced readmission among the $\mathrm{HHC}+$ cohort by $1.3 \%$. Diagnoses for readmission included arrhythmia (30\%), heart failure (18\%), infection $(7.9 \%)$, and transient ischemia/stroke (5.3\%). Compared with the HHC- cohort, $\mathrm{HHC}+$ patients had higher rates of readmission for infection and stroke, suggesting that HHC leads to earlier identification of these complications, necessitating appropriate readmission. Conversely, patients in the HHC+ cohort were less likely to be admitted for arrhythmias, suggesting that outpatient identification of arrhythmias results in alteration of medical therapy, thereby obviating readmission.

Limitations of this study relate to the lack of data regarding the specific nature of $\mathrm{HHC}$ services provided, and incomplete geographical, financial, and racial

\footnotetext{
From the Departments of ${ }^{\mathrm{a} C}$ Cardiology and ${ }^{\mathrm{b}}$ Cardiothoracic Surgery, Mayo Clinic Florida, Jacksonville, Fla.

Disclosure: Authors have nothing to disclose with regard to commercial support.

Received for publication Feb 21, 2020; accepted for publication Feb 21, 2020; available ahead of print March 12, 2020.

Address for reprints: Kevin P. Landolfo, MD, Department of Cardiothoracic Surgery, Mayo Clinic Florida, 4500 San Pablo Rd, Jacksonville, FL 32224 (E-mail: Landolfo.Kevin@mayo.edu).

J Thorac Cardiovasc Surg 2021;162:1740-1

0022-5223/\$36.00

Copyright (c) 2020 by The American Association for Thoracic Surgery

https://doi.org/10.1016/j.jtcvs.2020.02.108
}

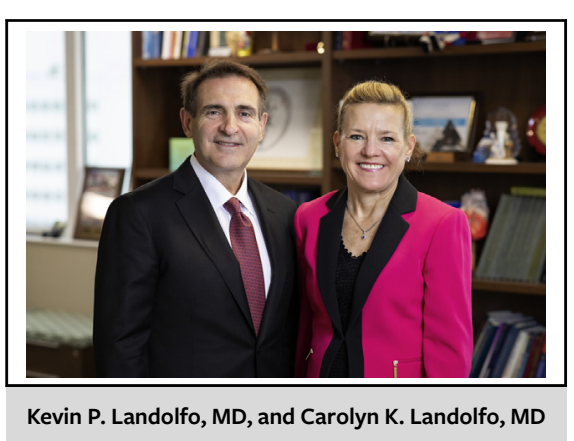

CENTRAL MESSAGE

Home health care services play a vital role in preventing hospital readmission following coronary artery bypass surgery.

representation. Despite these shortcomings, these data suggest that HHC positively influences postoperative readmission in the current demographic of CABG patients (ie, older, sicker, and with multiple comorbidities), and suggests that its utility may be extrapolated to other patients (eg, transcatheter aortic valve replacement or MitraClip [Abbott, Abbott Park, Ill]) at higher risk for readmission. Of note, Medicaid patients received HHC less frequently compared with patients with other insurance providers, further highlighting health care disparities among patients from lower socioeconomic backgrounds.

The association of $\mathrm{HHC}$ and reduction in hospital readmission following CABG warrants further speculation with regard to the transition of care from the acute episode, managed by a surgical team, to the longer-term care provided by cardiology and primary care. HHC plays a critical role in this transition, including not only services by trained medical personnel, but also by enhanced family support. These data highlight the importance of training home health teams and key family to identify postoperative problems and to establish guideline-driven pathways to prevent readmission. In this era of advanced technology, future HCC should include home video conferencing and remote arrhythmia monitoring.

On a final note, the findings in this study highlight an important concept of health care reform. ${ }^{5}$ Value indexing $(\mathrm{V}=\mathrm{Q} / \mathrm{C})$ defines the value $(\mathrm{V})$ of health care as the ratio between quality (Q) (ie, clinical outcomes, safety, and patient satisfaction) divided by the total cost (C) over time. Despite the short-term increase in cost of HCC in the 
immediate postoperative setting, value increases by both increasing quality and reducing cost over time by decreasing readmission. Thus, it takes a village-including HHC - for patients to transition from their index hospitalization to normal activity following CABG surgery.

\section{References}

1. Jencks SF, Williams MV, Coleman EA. Rehospitalizations among patients in the Medicare fee-for-service program. N Engl J Med. 2009;360:1418-28.
2. Bueno H, Ross JS, Wang Y, Chen J, Vidán MT, Normand SL, et al. Trends in length of stay and short-term outcomes among Medicare patients hospitalized for heart failure, 1993-2006. JAMA. 2010;303:2141-7.

3. McIlvennan CK, Eapen ZJ, Allen LA. Hospital readmissions reduction program. Circulation. 2015;131:1796-803

4. Deo SV, Sharma V, Altarabsheh SE, Raza S, Wilson B, Elgudin Y, et al. Home health care visits may reduce the need for early readmission after coronary artery bypass grafting. J Thorac Cardiovasc Surg. 2021;162: 1732-9.e4.

5. Kelly B. Mayo Clinic response to Senate Finance Committee. Available at: https:// www.mayoclinic.org/documents/mc-response-senate-finance-committee-5-13pdf/doc-20079654. Accessed March 14, 2020.
See Article page 1732.

\section{Commentary: Should patients receive home health care after coronary artery bypass grafting?}

\author{
Victor A. Ferraris, MD, PhD
}

In this issue of the Journal, an article by Deo and colleauges ${ }^{1}$ describes the potential benefits of home health visits following operative coronary artery revascularization (coronary artery bypass grafting [CABG]). The authors provide some evidence from the National Readmission Database (NRD) that suggests benefit from focused home health visits in a very specific postoperative population (ie, patients having first-time CABG). The results and conclusions reported by the authors are based on a database that lacks granularity, as is typical of administrative databases. As the authors point out, the in-depth assessments of the NRD are limited by the simplified definitions of readmission causes within the NRD. These limitations make it difficult to account for the differences in the causes of readmission rates between the home health group and the usual-care group of their study patients. The authors are cautious about advocating for the use of home health visits

\footnotetext{
From the Division of Cardiothoracic Surgery, Department of Surgery, University of Kentucky, Lexington, Ky.

Disclosures: Author has nothing to disclose with regard to commercial support.

Received for publication Feb 23, 2020; revisions received March 8, 2020; accepted for publication March 9, 2020; available ahead of print March 30, 2020.

Address for reprints: Victor A. Ferraris, MD, PhD, Division of Cardiothoracic Surgery, Department of Surgery, University of Kentucky, A301 Kentucky Clinic,

740 South Limestone, Lexington, KY 40536-0284 (E-mail: ferraris@uky.edu).

J Thorac Cardiovasc Surg 2021;162:1741-3

$0022-5223 / \$ 36.00$

Copyright (c) 2020 by The American Association for Thoracic Surgery

https://doi.org/10.1016/j.jtcvs.2020.03.050
}

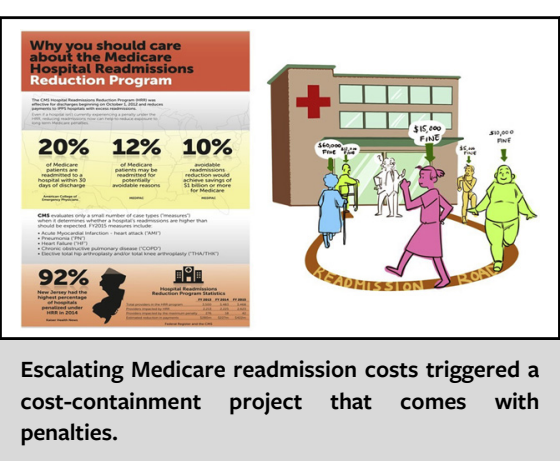

CENTRAL MESSAGE

Early home health care after CABG provides variable added value and is costly but not uniformly helpful.

to limit readmissions, but their evidence is provocative, and perhaps hypothesis generating.

Early, unplanned hospital readmissions following discharge after cardiac operations are common, occurring in $8 \%$ to $24 \%$ of discharged patients. ${ }^{2,3}$ There are wide variations in hospitals' readmission rates, with certain hospitals being outliers. ${ }^{4}$ Studies suggest that hospitals can actively lower their rate of readmissions by careful discharge planning. ${ }^{5,6}$ Interventions like clarifying patient discharge instructions, coordinating with postacute care providers, and reducing medical complications during initial hospitalization all may limit readmissions. Importantly, limitations of the NRD do not account for hospital and posthospital interventions that may limit readmissions, aside from home health visits. Discharge planning must be an important part of the postdischarge course of patients who undergo $\mathrm{CABG}$, and the exact extent of discharge planning for patients who undergo CABG is not accounted for in the NRD. 